\title{
Diminution of real power loss by novel gentoo penguin algorithm
}

\author{
Kanagasabai Lenin \\ Department of EEE, Prasad V. Potluri Siddhartha Institute of Technology, India
}

\begin{abstract}
In this paper Gentoo Penguin Algorithm (GPA) is proposed to solve optimal reactive power problem. Gentoo Penguins preliminary population possesses heat radiation and magnetizes each other by absorption coefficient. Gentoo Penguins will move towards further penguins which possesses low cost (elevated heat concentration) of absorption. Cost is defined by the heat concentration, distance. Gentoo Penguins penguin attraction value is calculated by the amount of heat prevailed between two Gentoo penguins. Gentoo Penguins heat radiation is measured as linear. Less heat is received in longer distance, in little distance, huge heat is received. Gentoo Penguin Algorithm has been tested in standard IEEE 57 bus test system and simulation results show the projected algorithm reduced the real power loss considerably.
\end{abstract}

This is an open access article under the CC BY-SA license.

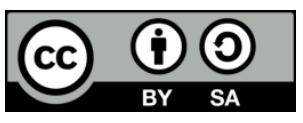

\section{Corresponding Author:}

Kanagasabai Lenin, Department of EEE, Prasad V. Potluri Siddhartha Institute of Technology, Kanuru, Vijayawada, Andhra Pradesh, 520007, India. Email: gklenin@gmail.com

\section{INTRODUCTION}

The main objective of optimal reactive power problem is to minimize the real power loss and bus voltage deviation. To till date various methodologies has been applied to solve the Optimal Reactive Power problem. The key aspect of solving Reactive Power problem is to reduce the real power loss. Previously many types of mathematical methodologies [1-6] have been utilized to solve the reactive power problem, but they lack in handling the constraints to reach global optimization solution. In the next level various types of evolutionary algorithms [7-15] has been applied to solve the reactive power problem. This paper proposes Gentoo Penguin Algorithm (GPA) to solve optimal reactive power problem. Gentoo Penguins will move towards further penguins which possesses low cost (elevated heat concentration) of absorption [16]. Gentoo Penguins preliminary population possesses heat radiation and magnetizes each other by absorption coefficient Cost is defined by the heat concentration, distance. Gentoo Penguins preliminary population possesses heat radiation and magnetizes each other by absorption coefficient Attraction is completed, a newfangled solution is estimated for that heat concentration is modernized. Solutions are arranged sequentially and most excellent is chosen. For heat radiation, movement, heat absorption damping ratio is applied. Gentoo penguin spiral movements throughout the absorption procedure are not droning and have a divergence with consistent distribution. Proposed Gentoo Penguin Algorithm (GPA) has been tested in standard IEEE 57 bus test system and simulation results show the projected algorithm reduced the real power loss effectively. 


\section{PROBLEM FORMULATION}

Real Power loss reduction is mathematically written by:

$$
\mathrm{F}=\mathrm{P}_{\mathrm{L}}=\sum_{\mathrm{k} \in \mathrm{Nbr}} \mathrm{g}_{\mathrm{k}}\left(\mathrm{V}_{\mathrm{i}}^{2}+\mathrm{V}_{\mathrm{j}}^{2}-2 \mathrm{~V}_{\mathrm{i}} \mathrm{V}_{\mathrm{j}} \cos \theta_{\mathrm{ij}}\right)
$$

with respect to voltage deviation,

$$
\begin{aligned}
& \mathrm{F}=\mathrm{P}_{\mathrm{L}}+\omega_{\mathrm{v}} \times \text { Voltage Deviation } \\
& \text { Voltage Deviation }=\sum_{\mathrm{i}=1}^{\mathrm{Npq}}\left|\mathrm{V}_{\mathrm{i}}-1\right|
\end{aligned}
$$

constraint (Equality)

$$
\mathrm{P}_{\mathrm{G}}=\mathrm{P}_{\mathrm{D}}+\mathrm{P}_{\mathrm{L}}
$$

constraints (Inequality)

$$
\begin{aligned}
& \mathrm{P}_{\text {gslack }}^{\min } \leq \mathrm{P}_{\text {gslack }} \leq \mathrm{P}_{\text {gslack }}^{\max } \\
& \mathrm{Q}_{\mathrm{gi}}^{\min } \leq \mathrm{Q}_{\mathrm{gi}} \leq \mathrm{Q}_{\mathrm{gi}}^{\max }, \mathrm{i} \in \mathrm{N}_{\mathrm{g}} \\
& \mathrm{V}_{\mathrm{i}}^{\min } \leq \mathrm{V}_{\mathrm{i}} \leq \mathrm{V}_{\mathrm{i}}^{\max }, \mathrm{i} \in \mathrm{N} \\
& \mathrm{T}_{\mathrm{i}}^{\min } \leq \mathrm{T}_{\mathrm{i}} \leq \mathrm{T}_{\mathrm{i}}^{\max }, \mathrm{i} \in \mathrm{N}_{\mathrm{T}} \\
& \mathrm{Q}_{\mathrm{c}}^{\min } \leq \mathrm{Q}_{\mathrm{c}} \leq \mathrm{Q}_{\mathrm{C}}^{\max }, \mathrm{i} \in \mathrm{N}_{\mathrm{C}}
\end{aligned}
$$

\section{GENTOO PENGUIN ALGORITHM}

In this proposed approach nature deeds of Gentoo penguin are imitated to model the Gentoo Penguin Algorithm (GPA). Gentoo penguin's position and cost are computed. Gentoo Penguins will move towards further penguins which possesses low cost (elevated heat concentration) of absorption. Cost is defined by the heat concentration, distance. Attraction is completed, a new-fangled solution is estimated for that heat concentration is modernized. Solutions are arranged sequentially and most excellent is chosen. For heat radiation, movement, heat absorption damping ratio is applied.

Rules are framed as follows:

- Gentoo Penguins preliminary population possesses heat radiation and magnetizes each other by absorption coefficient.

- Gentoo Penguins body surface area is considered equally.

- Gentoo Penguins absorb complete heat radiation

- Gentoo Penguins heat radiation is measured as linear.

- Gentoo Penguins penguin attraction value is calculated by the amount of heat prevailed between two Gentoo penguins. Less heat is received in longer distance, in little distance, huge heat is received.

- Gentoo penguin spiral movements throughout the absorption procedure are not droning and have a divergence with consistent distribution.

The surface area of the body of gentoo penguin is determined by,

$$
\text { Area }_{\text {trunk }}=2 \pi \frac{a b}{e} \sin ^{-1} e+2 \pi b^{2}
$$

COMPUTATION of Break area is done through,

$$
\text { Area }_{\text {break }}=\pi r s
$$

Head area of Gentoo penguin is calculated by,

$$
\text { Area }_{\text {head }}=\pi d^{2}-\pi r^{2}
$$


calculation of flipper is done through,

$$
\text { Area }_{\text {flipper }}=l \times w
$$

depending on the environment its has been assumed that gentoo penguin is in thermal equilibrium,

$$
q_{\text {total }}=q_{\text {trunk }}+q_{\text {head }}+q_{\text {flippers }}+q_{\text {feet }}
$$

from each body of gentoo penguin heat radiation emitted in that particular surface area is calculated by,

$$
Q_{\text {gentoo penguin }}=\operatorname{Area} \cdot \varepsilon \cdot \sigma \cdot T_{s}^{4}
$$

receiving the heat photons in the surface area is calculated by,

$$
I=I_{o}
$$

the intensity of the heat established at "I" at distance -"r" computed by

$$
I=I_{o} / r^{2}
$$

with the preliminary value $I_{o}$ when the heat source is linear at distance $r$,

$$
I=I_{o} / r
$$

attenuation of photon is given by,

$$
I=I_{o} e^{-\mu x}
$$

the attractiveness is defined by,

$$
Q=\operatorname{Area} \cdot \varepsilon \cdot \sigma \cdot T_{s}^{4} \cdot e^{-\mu x}
$$

logarithmic spiral movement of gentoo penguin is found by,

$$
\begin{aligned}
& r=a e^{b \theta} \\
& x=r \cos \theta=a \cos \theta e^{b \theta} \\
& y=r \sin \theta=a \sin \theta e^{b \theta}
\end{aligned}
$$

distance between two Gentoo penguins " $i$ "and " $j$ " is computed to calculate the spiral movement by,

$$
\begin{aligned}
D_{i j} & =\int_{i}^{j} d s=\int_{\theta i}^{\theta j} \sqrt{\left(\frac{d r}{d \theta}\right)^{2}+r^{2} d \theta}=\int_{\theta i}^{\theta j} \sqrt{a^{2} b^{2} e^{2 b \theta}+a^{2} e^{2 b \theta} d \theta} \\
& =a \sqrt{b^{2}+1} \int_{\theta i}^{\theta j} e^{b \theta} d \theta=\frac{a}{b} \sqrt{b^{2}+1}\left(e^{b \theta j}-e^{\theta i}\right)
\end{aligned}
$$

then the distance is calculated by,

$$
\begin{aligned}
& D_{i k}=Q \frac{a}{b} \sqrt{b^{2}+1}\left(e^{b \theta j}-e^{\theta i}\right)=\int_{i}^{k} d s=\frac{a}{b} \sqrt{b^{2}+1}\left(e^{b \theta k}-e^{\theta i}\right) \\
& \theta=\tan ^{-1} \frac{y}{x} \\
& x_{k}=a \cos \theta_{k} e^{b \theta_{k}} \\
& y_{k}=a \sin \theta_{k} e^{b \theta_{k}}
\end{aligned}
$$


then the components of the position is obtained by,

$$
\begin{aligned}
& x_{k}=a e^{b \frac{1}{b} \operatorname{In}\left\{(1-Q) e^{b \tan ^{-1} \frac{y_{i}}{x_{i}}}+Q e^{b \tan ^{-1} \frac{y_{j}}{x_{j}}}\right\}} \cos \left\{\frac{1}{b} \operatorname{In}\left\{(1-Q) e^{b \tan ^{-1} \frac{y_{i}}{x_{i}}}+Q e^{b \tan ^{-1} \frac{y_{j}}{x_{j}}}\right\}\right\} \\
& y_{k}=a e^{b \frac{1}{b} \operatorname{In}\left\{(1-Q) e^{b \tan ^{-1} \frac{y_{i}}{x_{i}}}+Q e^{b \tan ^{-1} \frac{y_{j}}{x_{j}}}\right\}} \sin \left\{\frac{1}{b} \operatorname{In}\left\{(1-Q) e^{b \tan ^{-1} \frac{y_{i}}{x_{i}}}+Q e^{b \tan ^{-1} \frac{y_{j}}{x_{j}}}\right\}\right\}
\end{aligned}
$$

spiral movement of Gentoo penguin $i$ summed with random vector and moved to new position by

$$
\begin{aligned}
& x_{k}=a e^{b \frac{1}{b} \operatorname{In}\left\{(1-Q) e^{b \tan ^{-1} \frac{y_{i}}{x_{i}}}+Q e^{b \tan ^{-1} \frac{y_{j}}{x_{j}}}\right\}} \cos \left\{\frac{1}{b} \operatorname{In}\left\{(1-Q) e^{b \tan ^{-1} \frac{y_{i}}{x_{i}}}+Q e^{b \tan ^{-1} \frac{y_{j}}{x_{j}}}\right\}\right\}+\varphi \epsilon_{i} \\
& y_{k}=a e^{b \frac{1}{b} \operatorname{In}\left\{(1-Q) e^{b \tan ^{-1} \frac{y_{i}}{x_{i}}}+Q e^{b \tan ^{-1} \frac{y_{j}}{x_{j}}}\right\}} \sin \left\{\frac{1}{b} \operatorname{In}\left\{(1-Q) e^{b \tan ^{-1} \frac{y_{i}}{x_{i}}}+Q e^{b \tan ^{-1} \frac{y_{j}}{x_{j}}}\right\}\right\}+\varphi \epsilon_{i}
\end{aligned}
$$

a. Start

b. Engender preliminary population array of Gentoo penguin

c. Engender the position of each Gentoo penguin

d. Engender the cost of each Gentoo penguin

e. Find out the preliminary heat absorption coefficient

f. For $\mathrm{It}=1$ to Maximum Iteration do

g. Engender the replicate reproduction of population array;

h. For $\mathrm{i}=1$ to $\mathrm{n}$ population do

i. For $\mathrm{j}=1$ to $\mathrm{n}$ population do

j. if costj < costi; then

$\mathrm{k}$. Compute the heat radiation value by $Q_{\text {gentoo penguin }}=\operatorname{Area} \cdot \varepsilon \cdot \sigma \cdot T_{s}^{4}$

1. Compute the attractiveness value by $Q=\operatorname{Area} \cdot \varepsilon \cdot \sigma \cdot T_{s}^{4} \cdot e^{-\mu x}$

$\mathrm{m}$. Compute the coordinated spiral movement value by

$$
\begin{aligned}
& x_{k}=a e^{b \frac{1}{b} \operatorname{In}\left\{(1-Q) e^{b \tan ^{-1} \frac{y_{i}}{x_{i}}}+Q e^{b \tan ^{-1} \frac{y_{j}}{x_{j}}}\right\}} \cos \left\{\frac{1}{b} \operatorname{In}\left\{(1-Q) e^{b \tan ^{-1} \frac{y_{i}}{x_{i}}}+Q e^{b \tan ^{-1} \frac{y_{j}}{x_{j}}}\right\}\right\} \\
& y_{k}=a e^{b \frac{1}{b} \operatorname{In}\left\{(1-Q) e^{b \tan ^{-1} \frac{y_{i}}{x_{i}}}+Q e^{b \tan ^{-1} \frac{y_{j}}{x_{j}}}\right\}} \sin \left\{\frac{1}{b} \operatorname{In}\left\{(1-Q) e^{b \tan ^{-1} \frac{y_{i}}{x_{i}}}+Q e^{b \tan ^{-1} \frac{y_{j}}{x_{j}}}\right\}\right\}
\end{aligned}
$$

n. Find out new-fangled position by,

$$
\begin{aligned}
& x_{k}=a e^{b \frac{1}{b} \operatorname{In}\left\{(1-Q) e^{b \tan ^{-1} \frac{y_{i}}{x_{i}}}+Q e^{b \tan ^{-1} \frac{y_{j}}{x_{j}}}\right\}} \cos \left\{\frac{1}{b} \operatorname{In}\left\{(1-Q) e^{b \tan ^{-1} \frac{y_{i}}{x_{i}}}+Q e^{b \tan ^{-1} \frac{y_{j}}{x_{j}}}\right\}\right\}+\varphi \epsilon_{i} \\
& y_{k}=a e^{b \frac{1}{b} \operatorname{In}\left\{(1-Q) e^{b \tan ^{-1} \frac{y_{i}}{x_{i}}}+Q e^{b \tan ^{-1} \frac{y_{j}}{x_{j}}}\right\}} \sin \left\{\frac{1}{b} \operatorname{In}\left\{(1-Q) e^{b \tan ^{-1} \frac{y_{i}}{x_{i}}}+Q e^{b \tan ^{-1} \frac{y_{j}}{x_{j}}}\right\}\right\}++\varphi \epsilon_{i}
\end{aligned}
$$

o. Estimate new-fangled solutions;

p. End 
q. Arrange and discover most excellent solution;

r. Modernize the heat radiation value (drop off condition);

s. Modernize the mutation coefficient (drop off condition);

t. Modernize the heat absorption coefficient (enhanced mode);

u. End

\section{SIMULATION STUDY}

Proposed Gentoo Penguin Algorithm (GPA) has been tested, in IEEE 57 Bus system [17]. Table 1 shows the constraints of control variables, Table 2 shows the limits of reactive power generators and comparison results are presented in Table 3. Figure 1 shows the comparison of Real Power Loss and Figure 2 Indicate about the Real power loss reduction in percentage.

Table 1. Constraints of control variables

\begin{tabular}{llll}
\hline & Variables type & Minimum value (PU) & Maximum value (PU) \\
\hline \multirow{2}{*}{ IEEE 57 Bus } & Generator Voltage & 0.95 & 1.1 \\
& Transformer Tap & 0.9 & 1.1 \\
& VAR Source & 0 & 0.20 \\
\hline
\end{tabular}

Table 2. Constrains of reactive power generators

\begin{tabular}{llll}
\hline & Variables & Q Minimum $(\mathrm{PU})$ & Q Maximum $(\mathrm{PU})$ \\
\hline IEEE 57 Bus & 1 & -140 & 200 \\
& 2 & -17 & 50 \\
& 3 & -10 & 60 \\
6 & -8 & 25 \\
8 & -140 & 200 \\
9 & -3 & 9 \\
12 & -150 & 155 \\
\hline
\end{tabular}

Table 3. Simulation results of IEEE -57 system

\begin{tabular}{|c|c|c|c|c|c|c|}
\hline Control variables & Base case & MPSO [18] & PSO [18] & CGA [18] & AGA [18] & GPA \\
\hline VG 1 & 1.040 & 1.093 & 1.083 & 0.968 & 1.027 & 1.024 \\
\hline VG 2 & 1.010 & 1.086 & 1.071 & 1.049 & 1.011 & 1.027 \\
\hline VG 3 & 0.985 & 1.056 & 1.055 & 1.056 & 1.033 & 1.029 \\
\hline VG 6 & 0.980 & 1.038 & 1.036 & 0.987 & 1.001 & 1.017 \\
\hline VG 8 & 1.005 & 1.066 & 1.059 & 1.022 & 1.051 & 1.028 \\
\hline VG 9 & 0.980 & 1.054 & 1.048 & 0.991 & 1.051 & 1.023 \\
\hline VG 12 & 1.015 & 1.054 & 1.046 & 1.004 & 1.057 & 1.031 \\
\hline Tap 19 & 0.970 & 0.975 & 0.987 & 0.920 & 1.030 & 0.901 \\
\hline Tap 20 & 0.978 & 0.982 & 0.983 & 0.920 & 1.020 & 0.908 \\
\hline Tap 31 & 1.043 & 0.975 & 0.981 & 0.970 & 1.060 & 0.920 \\
\hline Tap 35 & 1.000 & 1.025 & 1.003 & $\mathrm{NR}^{*}$ & $\mathrm{NR}^{*}$ & 1.019 \\
\hline Tap 36 & 1.000 & 1.002 & 0.985 & $\mathrm{NR} *$ & $\mathrm{NR}^{*}$ & 1.028 \\
\hline Tap 37 & 1.043 & 1.007 & 1.009 & 0.900 & 0.990 & 1.021 \\
\hline Tap 41 & 0.967 & 0.994 & 1.007 & 0.910 & 1.100 & 0.912 \\
\hline Tap 46 & 0.975 & 1.013 & 1.018 & 1.100 & 0.980 & 1.021 \\
\hline Tap 54 & 0.955 & 0.988 & 0.986 & 0.940 & 1.010 & 0.934 \\
\hline Tap 58 & 0.955 & 0.979 & 0.992 & 0.950 & 1.080 & 0.931 \\
\hline Tap 59 & 0.900 & 0.983 & 0.990 & 1.030 & 0.940 & 0.942 \\
\hline Tap 65 & 0.930 & 1.015 & 0.997 & 1.090 & 0.950 & 1.048 \\
\hline Tap 66 & 0.895 & 0.975 & 0.984 & 0.900 & 1.050 & 0.919 \\
\hline Tap 71 & 0.958 & 1.020 & 0.990 & 0.900 & 0.950 & 1.028 \\
\hline Tap 73 & 0.958 & 1.001 & 0.988 & 1.000 & 1.010 & 1.036 \\
\hline Tap 76 & 0.980 & 0.979 & 0.980 & 0.960 & 0.940 & 0.945 \\
\hline Tap 80 & 0.940 & 1.002 & 1.017 & 1.000 & 1.000 & 1.028 \\
\hline QC 18 & 0.1 & 0.179 & 0.131 & 0.084 & 0.016 & 0.131 \\
\hline QC 25 & 0.059 & 0.176 & 0.144 & 0.008 & 0.015 & 0.145 \\
\hline QC 53 & 0.063 & 0.141 & 0.162 & 0.053 & 0.038 & 0.102 \\
\hline PG (MW) & 1278.6 & 1274.4 & 1274.8 & 1276 & 1275 & 1272.12 \\
\hline QC (Mvar) & 321.08 & 272.27 & 276.58 & 309.1 & 304.4 & 272.26 \\
\hline Reduction in PLoss (\%) & 0 & 15.4 & 14.1 & 9.2 & 11.6 & 26.76 \\
\hline Total PLoss (Mw) & 27.8 & 23.51 & 23.86 & 25.24 & 24.56 & 20.358 \\
\hline
\end{tabular}

NR* - Not reported. 


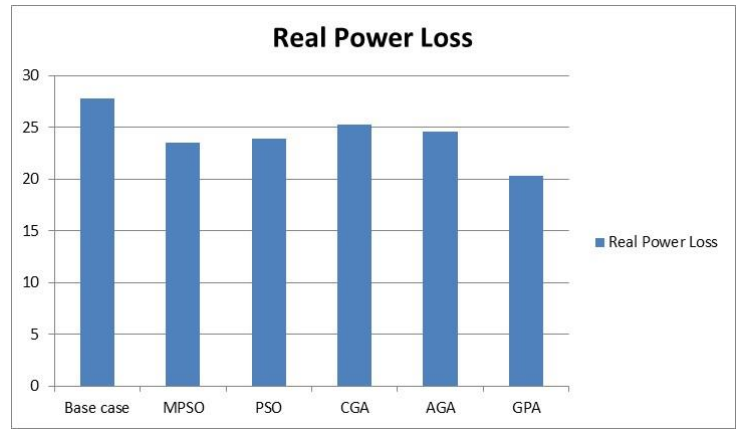

Figure 1. Comparison of real power loss

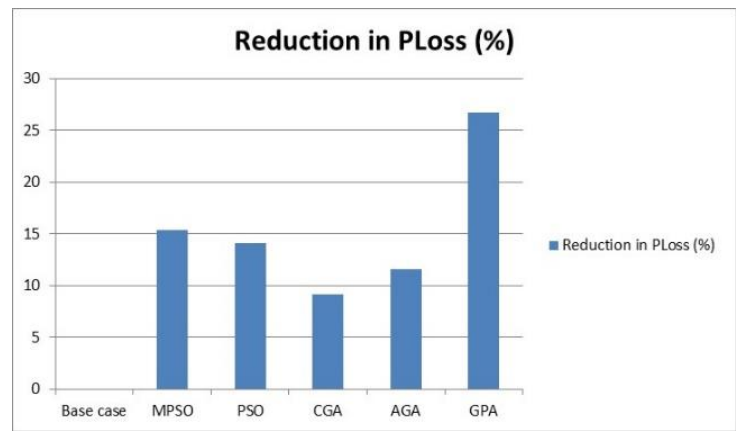

Figure 2. Real power loss reduction in percentage

\section{CONCLUSION}

Gentoo Penguin Algorithm (GPA) successfully solved the optimal reactive power problem. Gentoo Penguins penguin attraction value is calculated by the amount of heat prevailed between two Gentoo penguins. Less heat is received in longer distance, in little distance, huge heat is received. Depending on the environment its has been assumed that gentoo penguin is in thermal equilibrium. Proposed Gentoo Penguin Algorithm (GPA) has been tested in standard IEEE 57 bus test system and simulation results show the projected algorithm reduced the real power loss efficiently. And reduction of real power loss value is $26.76 \%$ when compared to the base value.

\section{REFERENCES}

[1] K. Y. Lee, "Fuel-cost minimisation for both real and reactive-power dispatches," Proceedings Generation, Transmission and Distribution Conference, vol. 131, no. 3, pp. 85-93, 1984.

[2] Aoki, K., A. Nishikori and R.T. Yokoyama, "Constrained load flow using recursive quadratic programming," IEEE T. Power Syst., vol. 2, no. 1, pp. 8-16, 1987.

[3] Kirschen, D.S. and H.P. Van Meeteren, "MW/voltage control in a linear programming based optimal power flow," IEEE T. Power Syst, vol. 3, no. 2, pp. 481-489. 1988.

[4] Liu, W.H.E., A.D. Papalexopoulos and W.F. Tinney, "Discrete shunt controls in a Newton optimal power flow," IEEE T. Power Syst, vol. 7, no. 4, pp. 1509-1518, 1992.

[5] V. H. Quintana and M. Santos-Nieto, "Reactive-power dispatch by successive quadratic programming," IEEE Transactions on Energy Conversion, vol. 4, no. 3, pp. 425-435, 1989.

[6] V. de Sousa, E. Baptista, and G. da Costa, "Optimal reactive power flow via the modified barrier Lagrangian function approach," Electric Power Systems Research, vol. 84, no. 1, pp. 159-164, 2012.

[7] Y. Li, X. Li, and Z. Li, "Reactive power optimization using hybrid CABC-DE algorithm," Electric Power Components and Systems, vol. 45, no. 9, pp. 980-989, 2017.

[8] S. Mouassa, T. Bouktir, and A. Salhi, "Ant lion optimizer for solving optimal reactive power dispatch problem in power systems," Engineering Science and Technology, an International Journal, vol. 20, no. 3, pp. 885-895, 2017.

[9] J. Ding, Q. Zhang, and Y. Ma, "Optimal reactive power dispatch based on the CS-PSO algorithm," in Proceedings of the 13th Conference on Industrial Electronics and Applications (ICIEA), IEEE, Wuhan, China, 2018.

[10] K. Abaci and V. Yamaçli, "Optimal reactive-power dispatch using differential search algorithm," Electrical Engineering, vol. 99, no. 1, pp. 213-225, 2017.

[11] J. Ding, Q. Zhang and Y. Ma, "Optimal reactive power dispatch based on the CS-PSO algorithm," 2018 13th IEEE Conference on Industrial Electronics and Applications (ICIEA), Wuhan, pp. 1172-1176, 2018.

[12] Thang Trung Nguyen, Dieu Ngoc Vo, Hai Van Tran, and Le Van Dai, "Optimal Dispatch of Reactive Power Using Modified Stochastic Fractal Search Algorithm,” Complexity, vol. 2019, Article ID 4670820, 28 pages, 2019.

[13] K. B. O. Medani, S. Sayah, and A. Bekrar, "Whale optimization algorithm based optimal reactive power dispatch: A case study of the Algerian power system," Electric Power Systems Research, vol. 163, pp. 696-705, 2018.

[14] Palappan, A., Thangavelu, J, "A New Meta Heuristic Dragonfly Optimizaion Algorithm for Optimal Reactive Power Dispatch Problem," Gazi University Journal of Science, vol. 31, pp. 1107-1121, 2018.

[15] K. Rayudu, G. Yesuratnam, and A. Jayalaxmi, "Ant colony optimization algorithm based optimal reactive power dispatch to improve voltage stability," in Proceedings of the 2017 IEEE International Conference on Circuit, Power and Computing Technologies, ICCPCT 2017, pp. 1-6, April 2017.

[16] R. C. Gerum, B. Fabry, C. Metzner, M. Beaulieu, A. Ancel and D. P. Zitterbart, "The origin of traveling waves in an emperor penguin huddle," New Journal of Physics, vol. 15, no. 12, 2013.

[17] IEEE, "The IEEE-test systems", 1993, www.ee.washington.edu/trsearch/pstca/.

[18] Ali Nasser Hussain, Ali Abdulabbas Abdullah and Omar Muhammed Neda, "Modified Particle Swarm Optimization for Solution of Reactive Power Dispatch," Research Journal of Applied Sciences, Engineering and Technology, vol. 15 , no. 8, pp. 316-327, 2018. 